\title{
Usefulness of Fluorine-18-Fluorodeoxyglucose Positron Emission Tomography in a Patient With Takayasu's Arteritis Associated With Antiphospholipid Syndrome
}

\author{
Bunji KAKU, ${ }^{1} \mathrm{MD}$, Takahiro HiguCHI, ${ }^{2} \mathrm{MD}$, Hounin KANAYA,${ }^{1} \mathrm{MD}$, \\ Yuki HorITA, ${ }^{1} \mathrm{MD}$, Tsukasa YAMAZAKI, ${ }^{1} \mathrm{MD}$, Yoshihide UNO,${ }^{1} \mathrm{MD}$, \\ Hideki ITOH, ${ }^{1} \mathrm{MD}$, Masanobu NAMURA, ${ }^{2} \mathrm{MD}$, and Masami SHIMIZU, ${ }^{3} \mathrm{MD}$
}

\begin{abstract}
SUMMARY
A 36-year-old woman was admitted for recurring chest pain and hemoptysis. Blood pressure in the right and left arms was equal, and no murmurs or bruits were heard. Body temperature was normal on admission and remained within the normal range during the hospital stay. C-reactive protein was slightly elevated $(2.3 \mathrm{mg} / \mathrm{dL})$ and lupus anticoagulant was positive. Angiography showed no abnormality of the aorta or its branches, but the left pulmonary artery showed occlusion at the proximal portion. Computed tomography (CT) revealed segmental wall thickening of the thoracic aorta. Fluorine-18-fluorodeoxyglucose positron emission tomography $\left({ }^{18} \mathrm{FDG}\right.$ PET) showed high uptake in the proximal portion of the left pulmonary artery and in the thoracic aorta with wall thickening on CT. Based on these findings, a diagnosis of Takayasu's arteritis associated with antiphospholipid syndrome was made and high-dose steroid therapy (prednisolone $30 \mathrm{mg} /$ day) was started. Two months later, the C-reactive protein level had decreased from $2.3 \mathrm{mg} / \mathrm{dL}$ to $1.1 \mathrm{mg} /$ $\mathrm{dL}$, and both the focal wall thickening and ${ }^{18} \mathrm{FDG}$ uptake of the thoracic aorta were decreased. ${ }^{18}$ FDG PET was useful for evaluating the efficacy of the steroid therapy in addition to making a diagnosis of Takayasu's arteritis associated with antiphospholipid syndrome. (Int Heart J 2006; 47: 311-317)
\end{abstract}

Key words: Takayasu's arteritis, Antiphospholipid syndrome, Positron-emission tomography

Although Takayasu's arteritis is a well-known disease, ${ }^{1,2)}$ it is relatively rare. The disease has various stages, and the symptoms and other clinical manifestations are different in each stage. Takayasu's arteritis affects the pulmonary artery as well as the aorta, ${ }^{3-5)}$ and pulmonary artery involvement predominates in some cases. ${ }^{5,6)}$ On the other hand, antiphospholipid syndrome is characterized by asso-

From the ${ }^{1}$ Division of Cardiology, Department of Internal Medicine, Ishikawa Prefectural Central Hospital, ${ }^{2}$ Divisions of Cardiology and Radiology, Kanazawa Cardiovascular Hospital, and ${ }^{3}$ Molecular Genetics of Cardiovascular Disorders, Division of Cardiovascular Medicine, Graduate School of Medical Science, Kanazawa University, Ishikawa, Japan.

Address for correspondence: Bunji Kaku, MD, Division of Cardiology, Department of Internal Medicine, Ishikawa Prefectural Central Hospital, Kuratsuki Higashi, Kanazawa, Ishikawa 920-8053, Japan.

Received for publication September 13, 2005.

Revised and accepted December 9, 2005. 
ciated arterial and venous thrombotic events. We encountered a patient with left pulmonary artery occlusion and positivity for lupus anticoagulant. The possibility of an association between the Takayasu's arteritis and antiphospholipid syndrome was considered. Several recent reports have described the usefulness of fluorine18-fluorodeoxyglucose positron emission tomography $\left({ }^{18}\right.$ FDG PET) for the evaluation of systemic inflammatory heart diseases. ${ }^{7-9)}$ Furthermore, the usefulness of ${ }^{18} \mathrm{FDG}$ PET/CT for the assessment of active atherosclerosis that contains an inflammatory component has been reported. ${ }^{10-13)}$

Therefore, we performed ${ }^{18}$ FDG PET for Takayasu's arteritis associated with antiphospholipid syndrome and found it to be useful for both the diagnosis and assessment of the condition of the arteritis during treatment.

\section{Case Presentation}

A 36-year-old woman with no history of pregnancy or abortion was admitted with recurrent chest pain and hemoptysis. Her symptoms had begun 8 months before, and showed no improvement. On physical examination, the blood pressure in her right and left arms was almost equal $(100 / 52 \mathrm{mmHg})$, and no heart murmurs or vascular bruits in the neck, chest, or abdomen could be heard. Body temperature was $36.2^{\circ} \mathrm{C}$ on admission, and remained within the normal range during her hospital stay. On admission, the C-reactive protein (CRP) level was slightly elevated $(2.3 \mathrm{mg} / \mathrm{dL})$ and the erythrocyte sedimentation rate was $70 \mathrm{~mm} /$ hr. The activated partial thromboplastin and prothrombin times were 42 seconds

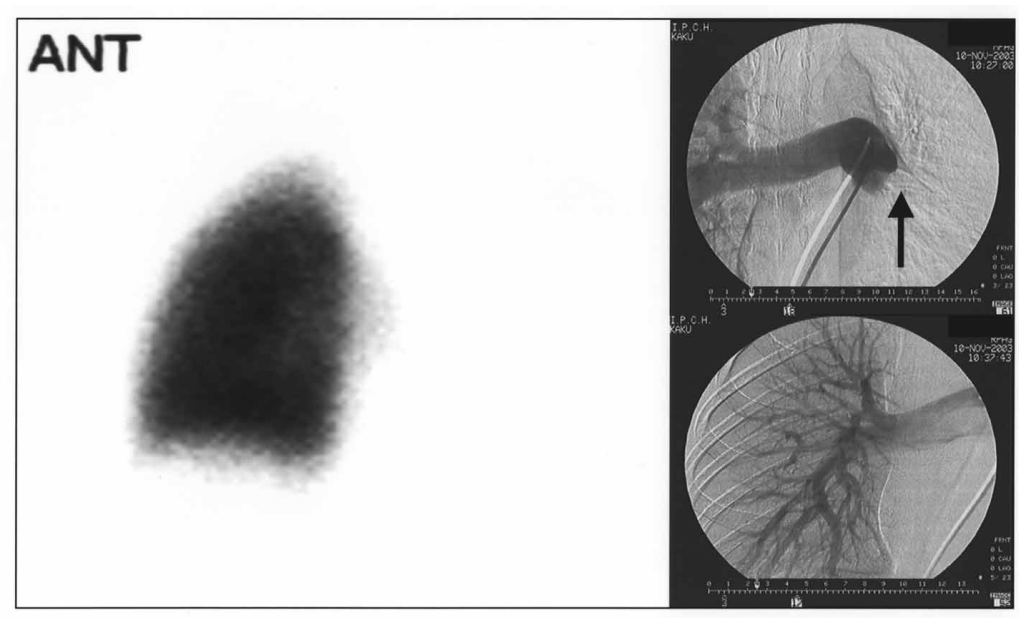

Figure 1. Left panel: Pulmonary blood flow scintigraphy shows no uptake in the left lung. Right panel: The left pulmonary artery is occluded at the proximal portion on pulmonary arteriography (black arrow). ANT indicates anterior. 
and 12 seconds, respectively. The antithrombin III, protein S, and protein C levels were within normal limits. Antinuclear antibody and anti-double-stranded-DNA antibody, proteinase-3-anti-neutrophil cytoplasmic antibody, and myeloperoxidase-anti-neutrophil cytoplasmic antibody were not detected and tests for syphilis were negative. Although IgG-anticardiolipin antibodies and anticardiolipin- $\beta 2$ glycoprotein I complex antibody were negative, lupus anticoagulant was positive. Pulmonary perfusion scintigraphy showed no uptake in the left lung, and pulmonary arteriography showed a proximal occlusion of the left pulmonary artery

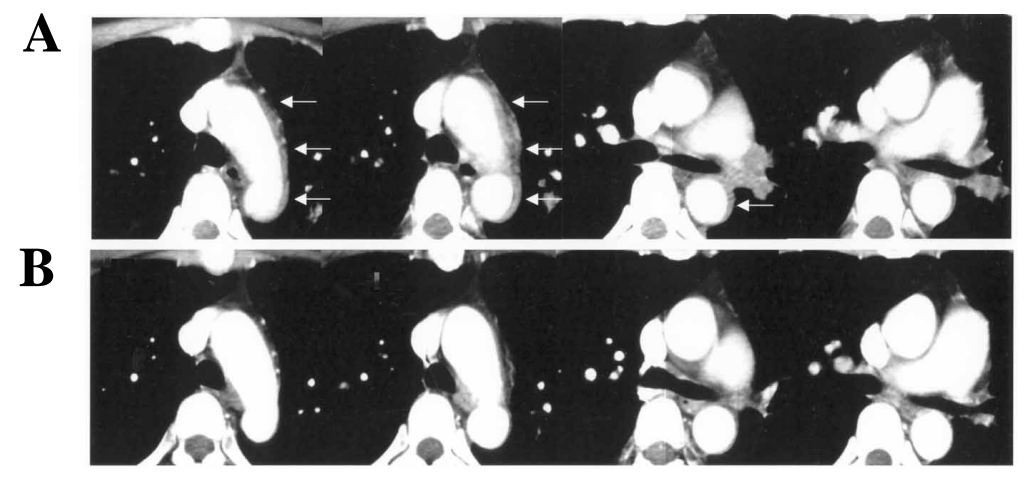

Figure 2. Computed tomography. A: Before treatment. White arrows show segmental wall thickening in the thoracic aorta. The proximal part of the left pulmonary artery is occluded. B: Two months after starting steroid therapy, the wall thickening in the aorta had disappeared.

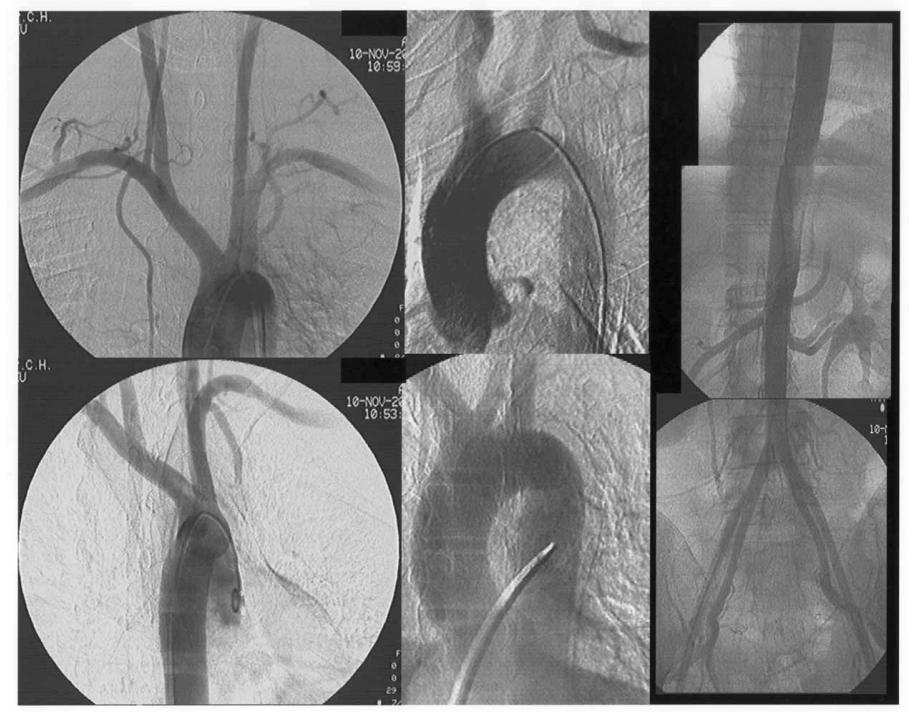

Figure 3. Angiograms of the aorta show no stenosis, occlusion, irregularity of the wall, or aneurysm formation. 
(Figure 1). Computed tomography (CT) showed segmental thickening of the wall of the thoracic aorta (Figure 2A). In this patient, the possibility of the coexistence of Takayasu's arteritis and antiphospholipid syndrome was considered. Angiography of the aorta disclosed no stenosis, occlusion, or dilation of the aorta or its branches, and the wall of the aorta was smooth (Figure 3). Ophthalmologic findings were also normal. To confirm the inflammatory change of the vascular walls, ${ }^{18}$ FDG PET/CT imaging (e-NTEGRA; GE Medical System, USA) was performed after more than 6 hours of fasting. ${ }^{18}$ FDG PET demonstrated high uptake in the proximal portion of the left pulmonary artery and in the wall of the thoracic aorta with thickening in the CT (Figure 4). We concluded that the uptake of

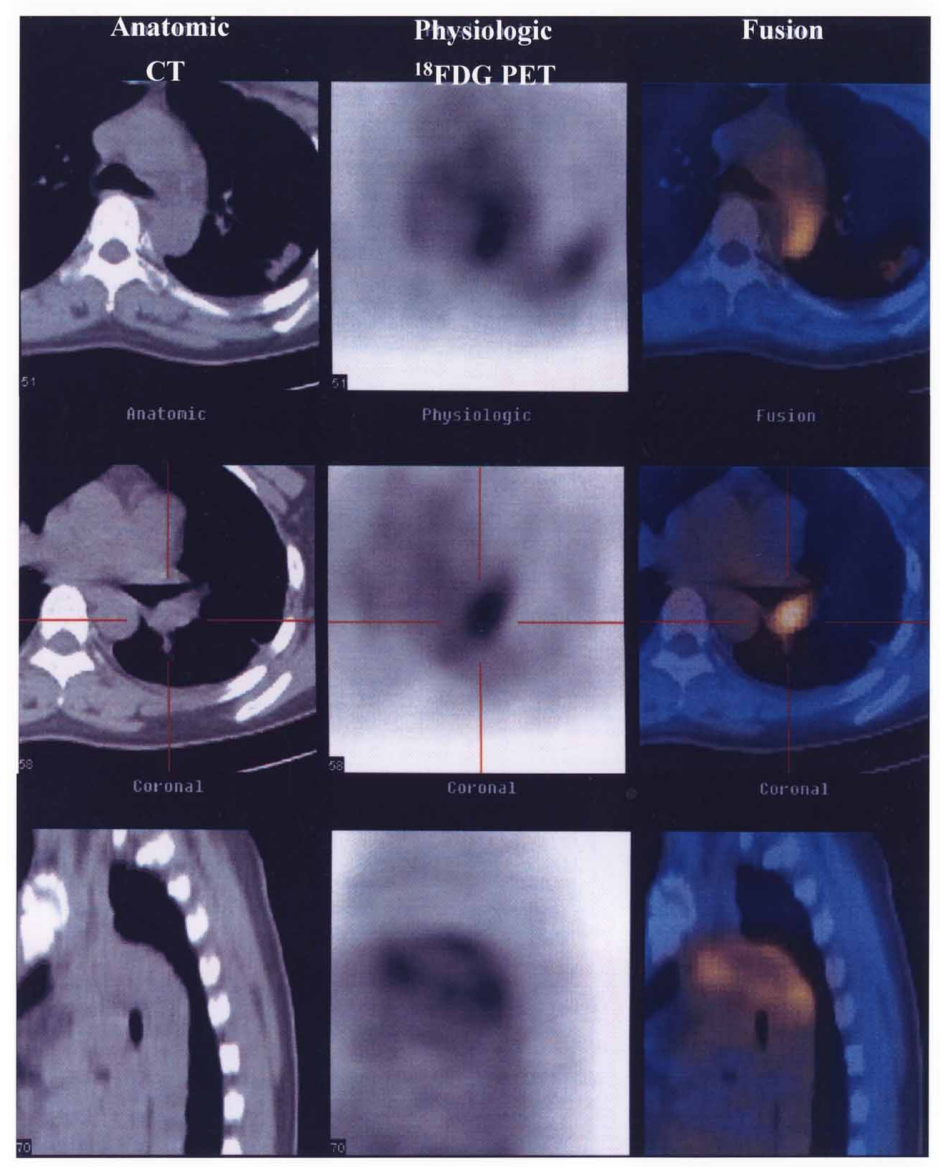

Figure 4. Computed tomography (left), fluorine-18-fluorodeoxyglucose positron emission tomography (center), and fusion images (right) before steroid treatment. High uptake of ${ }^{18}$ FDG PET was observed in the proximal portion of the left pulmonary artery and in the wall of the thoracic aorta that showed wall thickening on CT. 

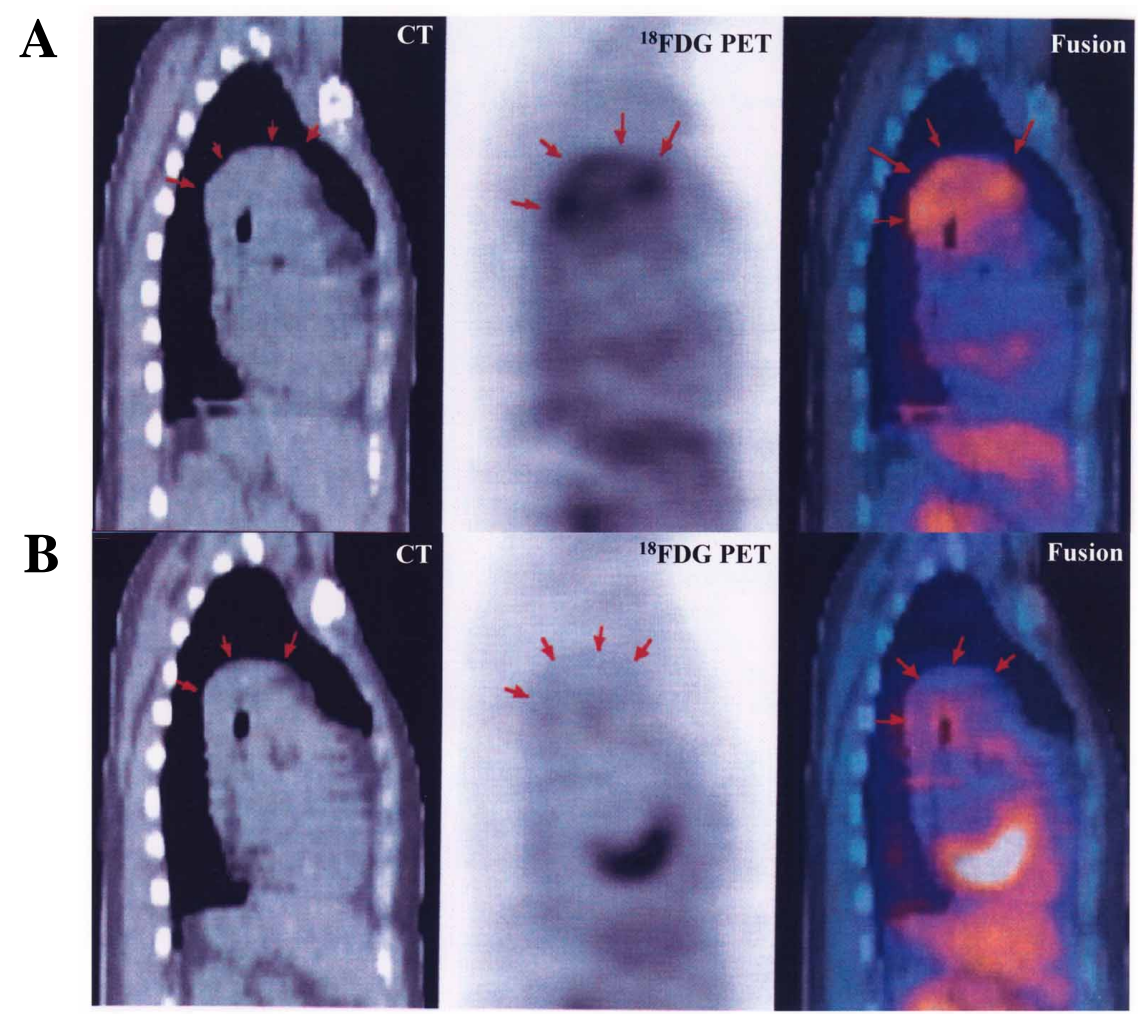

Figure 5. High uptake of fluorine-18-fluorodeoxyglucose positron emission tomography $\left({ }^{18} \mathrm{FDG}\right.$ PET) in the aortic wall disappeared after 2 months of steroid therapy. A (upper panels): Before steroid therapy. B (lower panels): After steroid therapy. CT indicates computed tomography.

${ }^{18}$ FDG PET most likely reflected inflammation of the arterial wall, and made a diagnosis of Takayasu's arteritis. High-dose steroid therapy (prednisolone $30 \mathrm{mg} /$ day) was then started. Two months later, the C-reactive protein level had decreased from $2.3 \mathrm{mg} / \mathrm{dL}$ to $1.1 \mathrm{mg} / \mathrm{dL}$. In addition, thickening of the thoracic aorta wall had decreased (Figure 2B) and the high uptake on ${ }^{18}$ FDG PET had disappeared (Figure 5).

\section{DISCUSSION}

Although the angiographic findings for the aorta in this patient were normal, the mild increase in CRP and segmental wall thickening of the thoracic aorta on CT suggested the likelihood of an inflammatory disease such as Takayasu's arteritis. On the other hand, however, a few reports have described an association between arteritis and antiphospholipid syndrome, ${ }^{14-16)}$ although such an associa- 
tion is uncommon. Furthermore, classically antiphospholipid syndrome is not considered as a vasculitis, and corticosteroids are not effective. In contrast, they are effective for Takayasu's arteritis. Therefore, it was important to confirm the existence of arteritis associated with antiphospholipid syndrome in this patient. We hesitated to treat this patient until a conclusive diagnosis of arteritis could be made. Even high-dose steroid therapy is not particularly effective for antiphospholipid syndrome, and carries a risk of considerable side effects.

Glycolytic metabolism is increased in inflammatory lesions and the usefulness of ${ }^{18}$ FDG PET for the evaluation of systemic inflammatory heart diseases and active atherosclerosis which contains the inflammatory component has been reported. ${ }^{7-13)}$ Therefore, we performed ${ }^{18}$ FDG PET in order to detect inflammation in this patient. The results of ${ }^{18}$ FDG PET study permitted a conclusive diagnosis of arteritis and an initiation of high-dose steroid therapy.

The early stage of Takayasu's arteritis shows inflammatory thickening of the aortic wall, while in the advanced stage, the aorta exhibits stenosis, occlusion, or aneurysm formation. Thus, initiation of steroid therapy during the early phase of arteritis is important to prevent irreversible structural changes to the aortic wall. Meller, et $a l^{17)}$ performed ${ }^{18}$ FDG PET in 5 patients with early Takayasu's arteritis and high uptake of ${ }^{18}$ FDG PET in the wall of the aorta was noted in all. They emphasized the usefulness of ${ }^{18}$ FDG PET for the diagnosis of early Takayasu's arteritis. In our case, ${ }^{18}$ FDG PET was very useful for the diagnosis of pulmonary artery and thoracic aorta involvement in the Takayasu's arteritis. In addition, ${ }^{18}$ FDG PET was also useful to evaluate the efficacy of steroid therapy.

The present patient gave permission for publication of the report and ${ }^{18} \mathrm{FDG}$ PET for arteritis was approved by our Hospital Ethics Committee.

\section{REFERENCES}

1. Takayasu M. A case with unusual changes of the central vessels in retina. Acta Soc Ophthalmol Jpn 1908; 12: 554-5. (Japanese)

2. Numano F, Okawara M, Inomata H, Kobayashi Y. Takayasu's arteritis. Lancet 2000; 356: 1023-5.

3. Lupi E, Sanchez G, Horwitz S, Gutierrez E. Pulmonary artery involvement in Takayasu's arteritis. Clinical Conference in Cardiology from the third medical division, Kyoto University Hospital, Kyoto, Japan. Chest 1975; 67: 69-74.

4. "Pulmonary pulseless disease": Pulmonary involvement in so-called Takayasu's disease. Clinical Conference in Cardiology from the third medical division, Kyoto University Hospital, Kyoto, Japan. Chest 1978; 73: 651-7.

5. Shikata H, Sakamoto S, Ueda Y, et al. Reconstruction of bilateral branch pulmonary artery stenosis caused by Takayasu's aortitis. Circ J 2004; 68: 791-4.

6. Lie JT. Isolated pulmonary Takayasu arteritis: clinicopathologic characteristics. Mod Pathol 1996; 9: 469-74.

7. Takeda N, Yokoyama I, Hiroi Y, et al. Positron emission tomography predicted recovery of complete A-V nodal dysfunction in a patient with cardiac sarcoidosis. Circulation 2002; 105: 1144-5.

8. Yamagishi $\mathrm{H}$, Shirai N, Takagi M, et al. Identification of cardiac sarcoidosis with ${ }^{13} \mathrm{~N}-\mathrm{NH}_{3} /{ }^{18} \mathrm{~F}-\mathrm{FDG}$ PFT. J Nucl Med 2003; 44: 1030-6. 
9. Morita H, Yokoyama I, Yamada N, Uno K, Nagai R. Usefulness of ${ }^{18} \mathrm{FDG} /{ }^{13} \mathrm{~N}$-ammonia PET imaging for evaluation of the cardiac damage in Churg-Strauss syndrome. Eur J Nucl Med Mol Imaging 2004; 31: 1218.

10. Tatsumi M, Cohade C, Nakamoto Y, Wahl RL. Fluorodeoxyglucose uptake in the aortic wall at PET/CT: possible finding for active atherosclerosis. Radiology 2003; 229: 831-7.

11. Ben-Haim S, Kupzov E, Tamir A, Israel O. Evaluation of ${ }^{18} \mathrm{~F}-\mathrm{FDG}$ uptake and arterial wall calcifications using ${ }^{18}$ F-FDG PFT/CT. J Nucl Med 2004; 45: 1816-21.

12. Tawakol A, Migrino RQ, Hoffman U, et al. Noninvasive in vivo measurement of vascular inflammation with F-18 fluorodeoxyglucose positron emission tomography. J Nucl Cardiol 2005; 12: 294-301.

13. Bengel FM. The atherosclerotic plaque: a healthy challenge to the limits of nuclear imaging. J Nucl Cardiol 2005; $12: 255-7$.

14. Yokoi K, Hosoi E, Akaike M, Shigekiyo T, Saito S. Takayasu's arteritis associated with antiphospholipid antibodies. Report of two cases. Angiology 1996; 47: 315-9.

15. Fain O, Mathieu E, Seror O, et al. Aortitis: a new manifestation of primary antiphospholipid syndrome. $\mathrm{Br} \mathrm{J}$ Rheumatol 1995; 34: 686-7.

16. Seror O, Fain O, Dordea M, Ghenassia C, Coderc E, Sellier N. Aortitis with antiphospholipid antibodies: CT and MR findings. Eur Radiol 1998; 8: 1373-5.

17. Meller J, Grabbe E, Becker W, Vosshenrich R. Value of F-18 FDG hybrid camera PET and MRI in early Takayasu aortitis. Eur Radiol 2003; 13: 400-5. 